
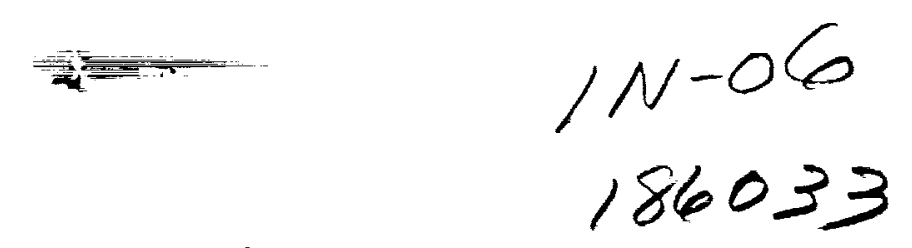

NASA Technical Memorandum 4504

$22 \rho$

\title{
Recent Flight-Test Results of Optical Airdata Techniques
}

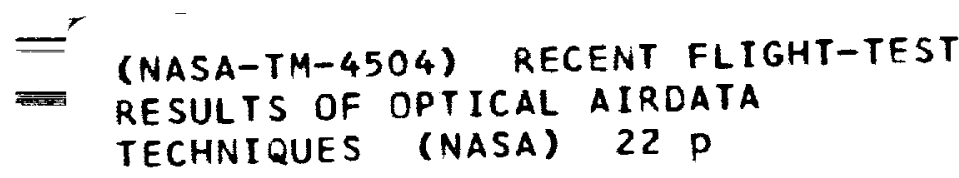

Unclas

Rodney K. Bogue

Dryden Flight Research Facility

Edwards, California

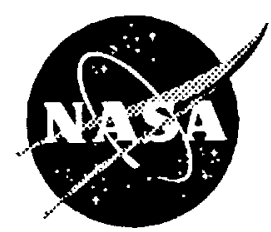

National Aeronautics and Space Administration Office of Management Scientific and Technical Information Program 
NASA Technical Memorandum 4504

\section{Recent Flight-Test \\ Results of Optical Airdata Techniques}

Rodney K. Bogue

MAY 1993

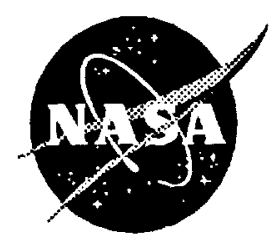





\title{
RECENT FLIGHT-TEST RESULTS OF OPTICAL AIRDATA TECHNIQUES
}

\author{
Rodney K. Bogue \\ NASA Dryden Flight Research Facility \\ P.O. Box 273 \\ Edwards, California 93523-0273
}

\begin{abstract}
Optical techniques for measuring airdata parameters have been demonstrated with promising results on high-performance fighter aircraft. These systems can measure the airspeed vector, and some are not as dependent on special in-flight calibration processes as current systems. Optical concepts for measuring freestream static temperature and density are feasible for in-flight applications. The best feature of these concepts is that the airdata measurements are obtained nonintrusively, and for the most part well into the freestream region of the flow field about the aircraft. Current requirements for measuring airdata at high angle of attack, and future need to measure the same information at hypersonic flight conditions place strains on existing techniques. Optical technology advances show outstanding potential for application in future programs and promise to make common use of optical concepts a reality. This paper summarizes results from several flight-test programs and identifies the technology advances required to make optical airdata techniques practical.
\end{abstract}

\section{INTRODUCTION}

This document is an overview of recent test results of optically based airdata measurement. As background for the overview, the measurement problem is defined, existing techniques are assessed, and the shortcomings are identified. Four different activities involving the flight testing of optical airdata measurement techniques are reviewed and conclusions are developed. In summary, conclusions are drawn and technology advances are identified that will be needed to bring optical airdata sensing into common, everyday use for military and commercial applications.

\section{THE MEASUREMENT PROBLEM}

Reference freestream airdata is important in flight testing and in flight operations for many reasons. The correlation of wind tunnel and flight-test results relies on freestream airdata for comparison. Most aerodynamic flight data obtained from different aircraft or from the same aircraft on different flights must be normalized using freestream airdata as the normalizing term. Flight research demands high-quality data and for this reason, the airdata information in research situations must be accurate. In many flight-control systems, airdata is used as a scaling factor and must therefore be highly robust to assure reliable flight vehicle operation. Acquiring airdata for hypersonic flight is difficult. Conventional pressure-based airdata sensing is impractical because of the extreme environment. Because of the important role that it plays in flight research and in operational control of aircraft systems, much effort is expended to obtain accurate, repeatable, and reliable airdata.

To identify the freestream situation, the following parameters must be known:

Airspeed - this vector quantity is most often specified by the airspeed magnitude with two flow direction angles as follows:

Flow angles defined in Fig. 1 as: ${ }^{1}$

Angle of attack $(\alpha)-\arctan (\mathrm{U} / \mathrm{V})$ 
Angle of sideslip $(\beta)-\arcsin (u / v)$

Ambient conditions - also termed freestream conditions. Defines the atmospheric conditions found outside the locally disturbed flow field that extends some distance from the flight vehicle.

Figure 1 illustrates the aircraft-referenced coordinate system used for the definition of flow direction angles. The airspeed vector is defined by the magnitude and direction of the aircraft motion relative to the atmosphere.

The ideal gas law requires that two of the three parameters be defined that comprise the ambient conditions (density, temperature, and pressure) in the gas equation of state. Other applications may require the measurement of other freestream parameters such as turbulence or gas constituents. Traditionally, the measured parameters have been pressure and temperature, primarily because these are relatively easy to measure with conventional temperature sensors and pressure transducers. Density traditionally has been difficult to measure directly and has not seen widespread use as a part of the ambient set of measurements.

Conventional measurements are obtained from within the disturbed local flow field and thus are subject to the effects of this field. The difficulty of measuring airdata in flight is partially illustrated in Fig. 2, which shows the effects of a moving object on the local flow field. This effect disturbs the local flow direction and the ambient condition measurements.

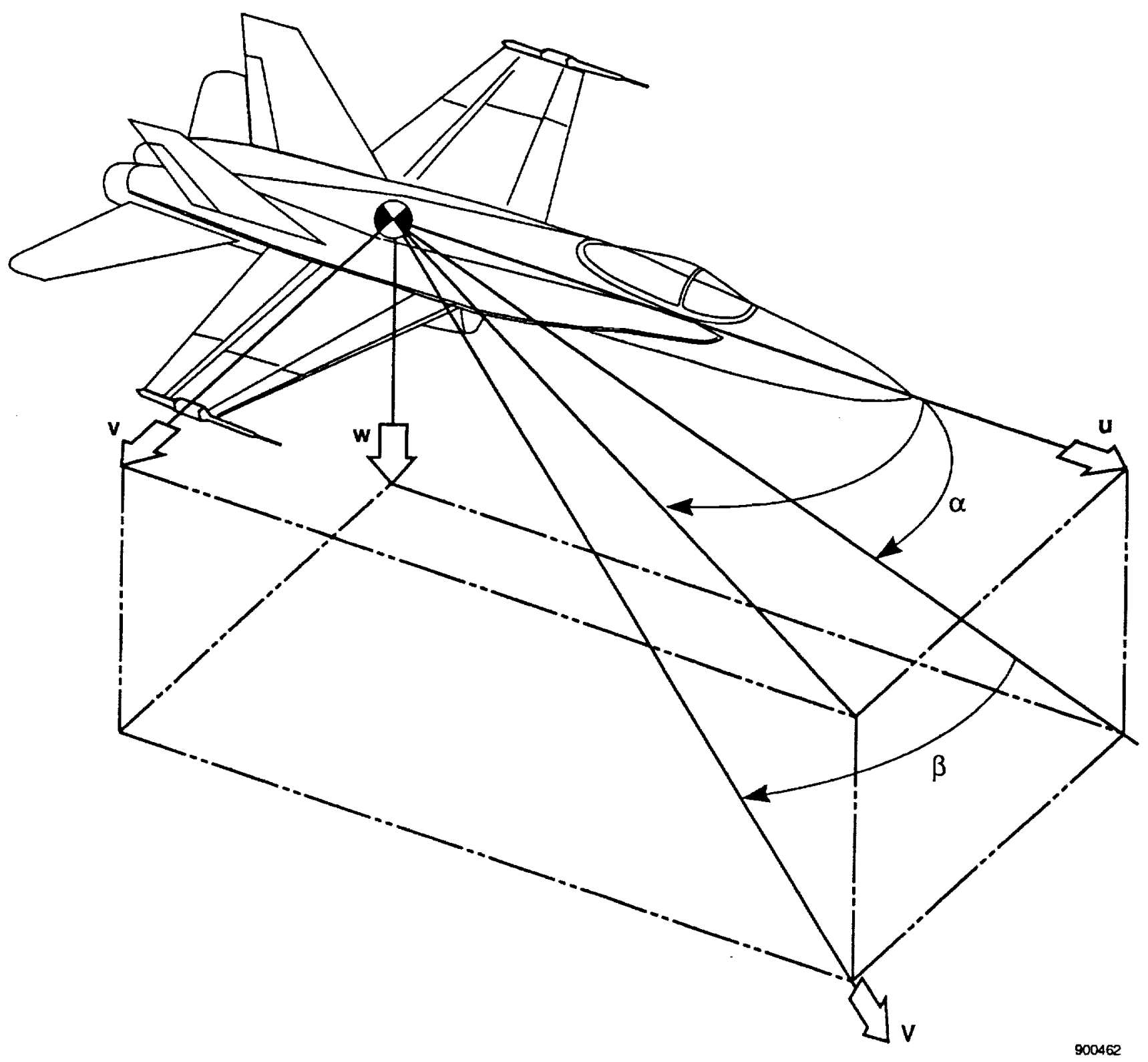

Fig. 1 The airspeed information set. 


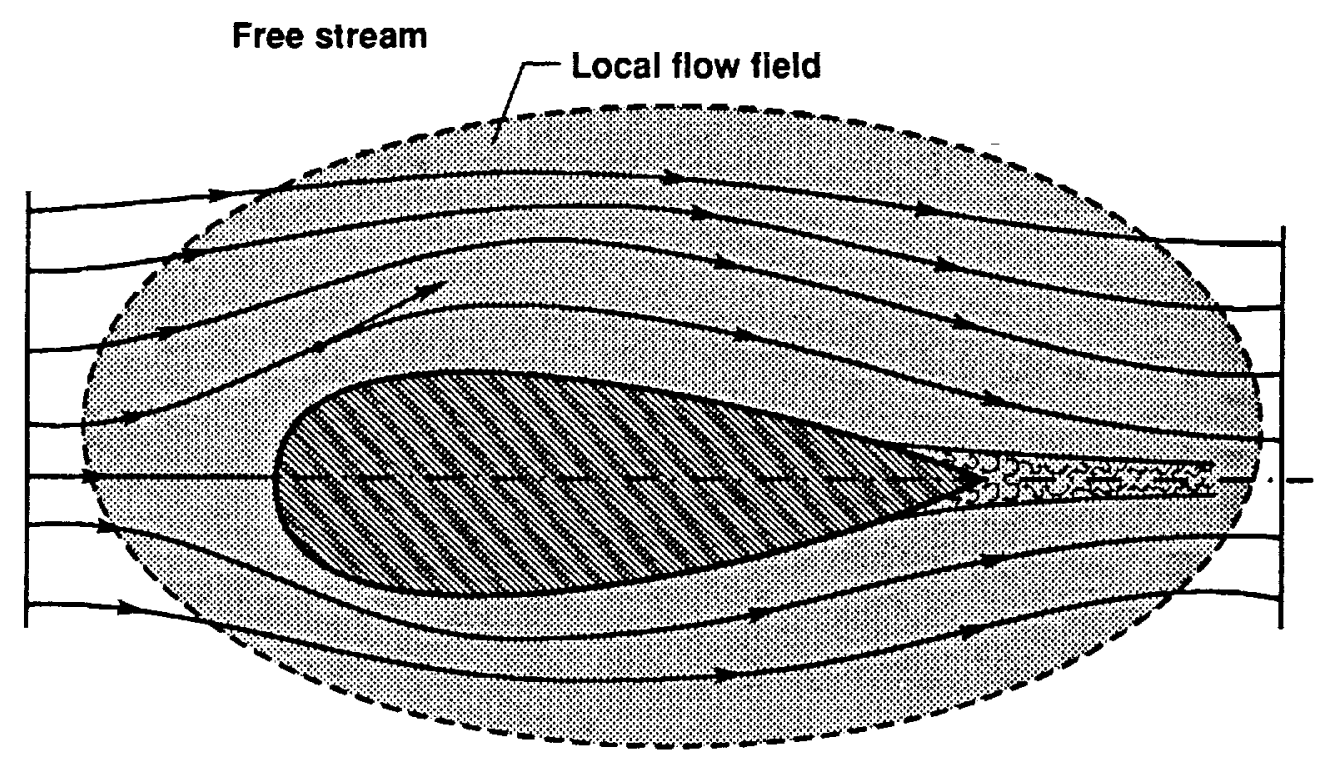

920556

Fig. 2 The measurement problem.

The aircraft motion creates a compression region in front of the aircraft and modified flow direction around the vehicle, both of which create disturbances in the ambient local pressure field. Surface static pressure orifice locations must be carefully selected to reduce local flow effects (termed position error). These local flow effects may cause the pressure measured at the static pressure orifice to be higher or lower than the true ambient pressure. Vehicle flow direction angles (angle of attack and angle of sideslip) as well as Mach number influence the correction factors that must be applied to the pressure measurements to account for the local flow effects. Total pressure is affected by the local flow field.

Distortions in the direction of the local flow (streamline) as it moves around the flight vehicle cause errors in the measurement of flow direction. These effects are most pronounced at high-angle-ofattack conditions that usually occur at low dynamic pressure situations. In this environment, the flow direction measurement vanes are deeply submerged into the circulating flow about the body of the aircraft and are measuring the local flow field direction at the vane location instead of at the desired freestream conditions.

Temperature measurements are affected by the local flow effects, and other measurement problems make acquiring quality temperature data difficult.
When air temperature is measured from a solid surface, the flow has been brought to rest (relative to the aircraft) on the surface of the measurement element. The flow velocity change from the freestream static state causes the measured air temperature to be increased. Static temperature provides the desired ambient state information, but because of the physical situation, a temperature above the ambient value is what is measured from a moving aircraft using an immersion sensor.

The ideal of measuring static temperature is never achieved using conventional techniques. The parameter that is most closely duplicated is total or stagnation temperature. Many other effects impact the temperature measurement, which is affected by thermal radiation errors, the presence of moisture, heat transfer coefficients, and flow effects at the surface of the measurement element. The difficulties in measuring temperature are compounded as the flight vehicle velocity increases.

All airdata measurements are made more difficult at high-angle-of-attack conditions and at high-speed flight conditions. For situations requiring accuracy, the pressure-based and temperature measurement techniques must be calibrated for local flow field effects. These difficulties could be eliminated if the measurements could be obtained outside the local flow field. 

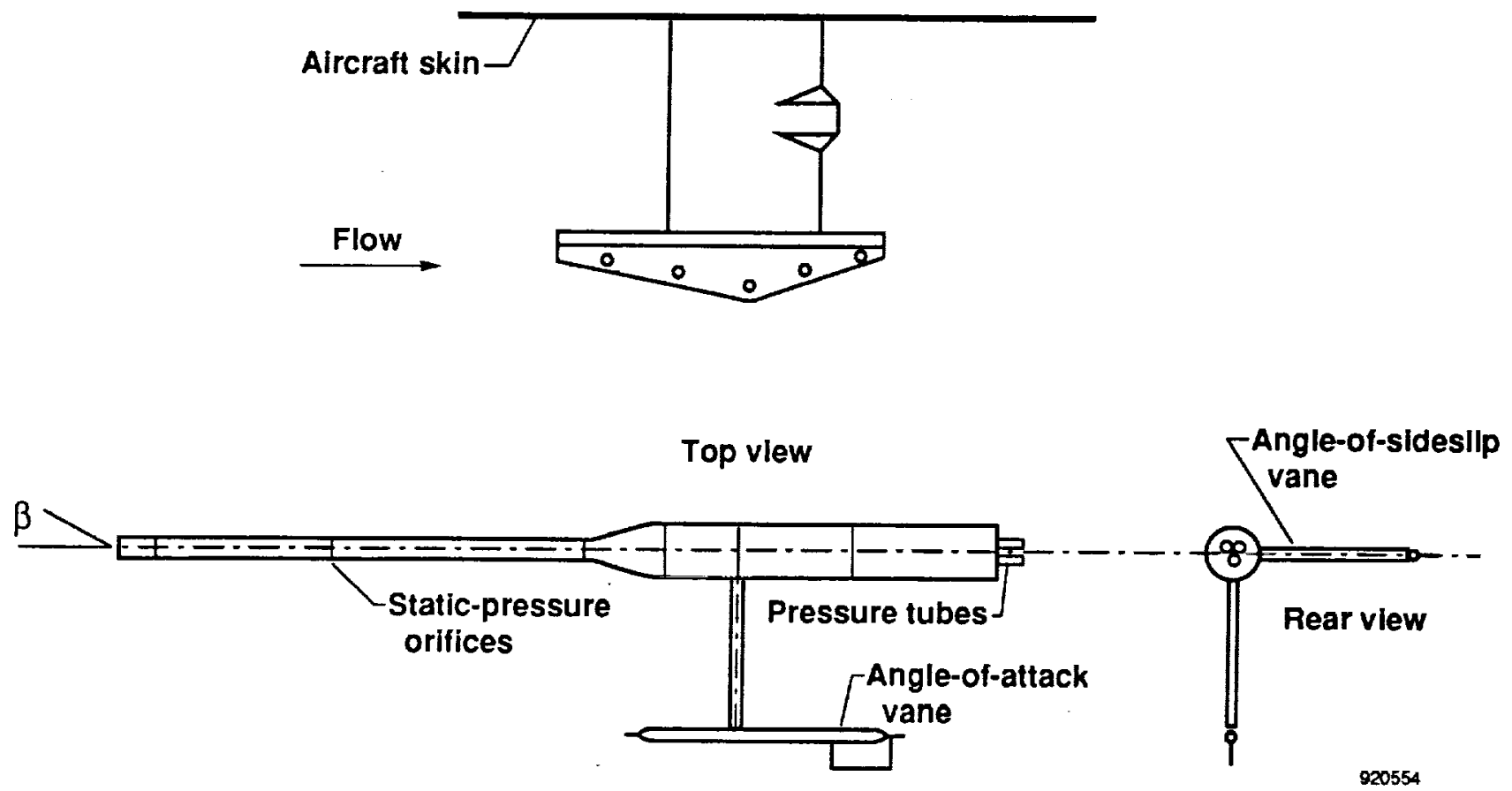

Fig. 3 Airdata boom with total temperature sensor.

\section{EXISTING METHODS AND LIMITATIONS}

For many years, the preferred research airdata measurement technique for high-performance applications has been an airdata boom attached to the nose of the aircraft. This boom includes orifices from which pressures are obtained to show total (or stagnation) air pressure and static air pressure. As shown in Fig. 3, this boom has self aligning measurement vanes which measure components of the flow direction.

Calibrated measurements from an airdata boom are satisfactory for most research applications for aircraft situations where $\alpha<20^{\circ}$ and $M<3.3$. Calibration for the error in ambient pressure measurement (position error) is performed as a function of Mach number and angle of attack using the tower fly-by technique for subsonic conditions and radar comparisons for supersonic flight regimes. Wellcalibrated boom measurements provide data accuracy of $M=.003 .^{2}$ Calibrating airdata boom systems is a time consuming and expensive process that must be done for each new aircraft requiring research-quality measurements.

For flight conditions above $\alpha=20^{\circ}$, the local flow conditions at the airdata boom location become increasingly complex. As the angle between the loca! flow direction and the boom axis increases, the flow conditions near the pressure orifices become less well-defined. These flow distortions affect total, static, and temperature measurements and at low dynamic pressure, airspeed is particularly sensitive to these effects. Poor pressure recovery at the total pressure orifice contributes to this measurement sensitivity. Figure 4 illustrates a modified airdata boom designed to swivel the total pressure orifice into the local streamline to improve pressure recovery.

Another difficulty with the airdata boom, revealed by flight research at high angle of attack, is that the boom disturbs the flow across the nose of highperformance aircraft. The vehicle flight characteristics are altered by the presence of an airdata boom. Figure 5 shows a flush airdata system (FADS) designed to measure flow direction, Mach number, and ambient pressure from multiple orifices on the vehicle nose and to eliminate the flow disturbance caused by the airdata boom. The FADS has been used successfully to measure airdata parameters, including measurements on the F-18 High Alpha Research Vehicle (HARV). ${ }^{3}$ The FADS eliminates the need for an airdata boom on the nose of the aircraft at the expense of an extensive calibration process which uses an airdata boom on each wingtip.

For flight conditions in the region of $M=3$ and above, conventional airdata booms would not 


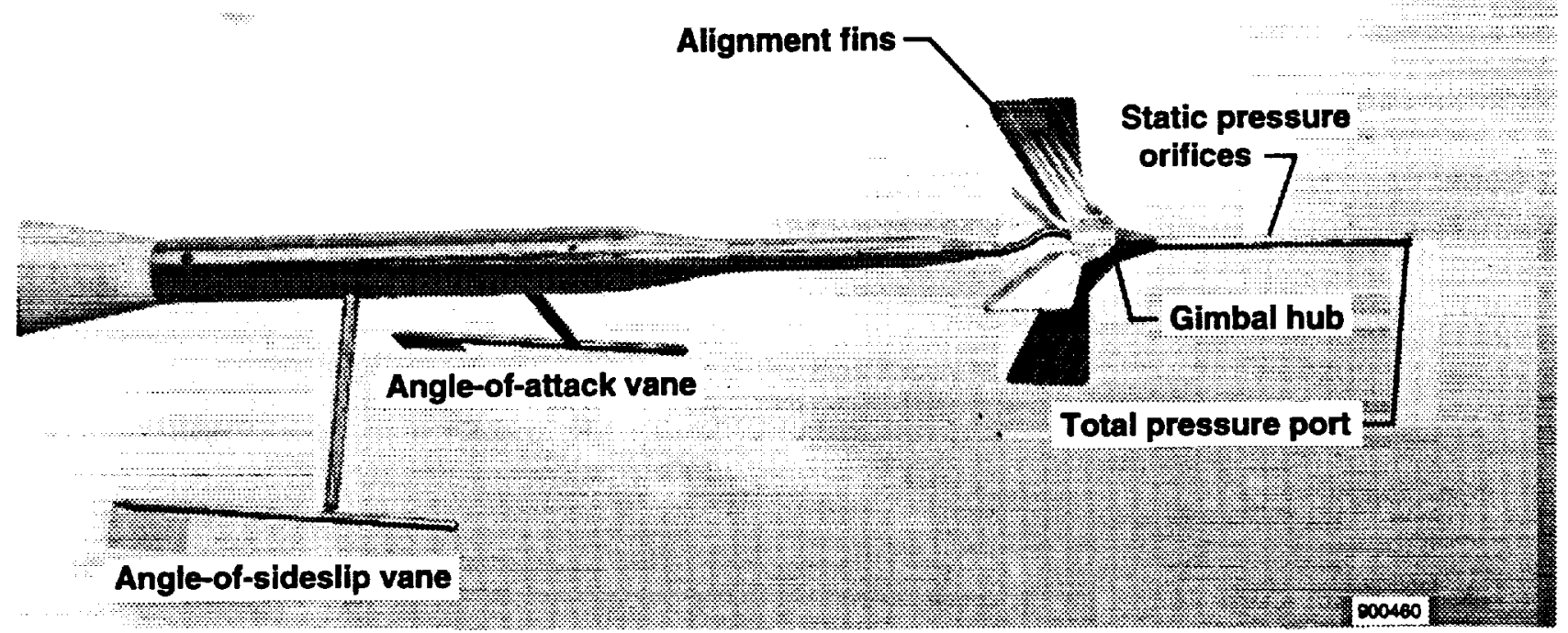

Fig. 4 Swiveling head airdata boom.

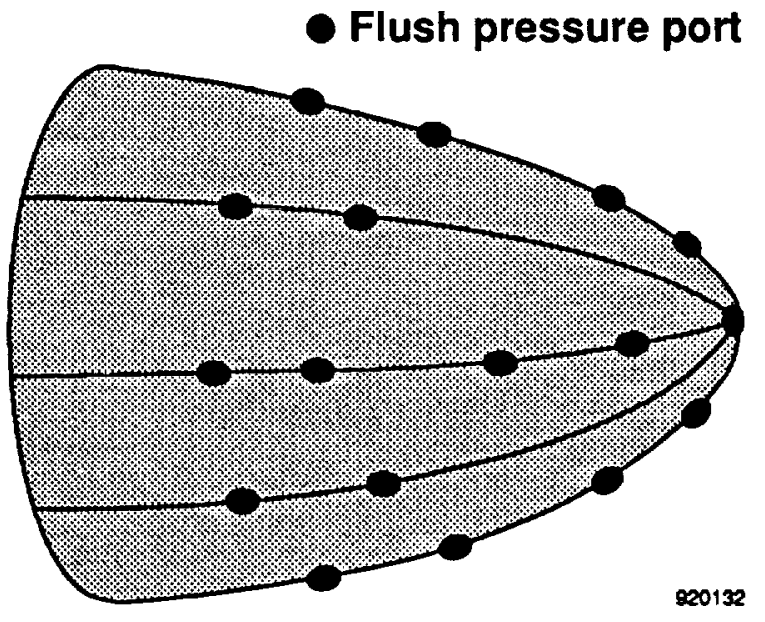

Fig. 5 Flush airdata system.

survive the thermal environment. A system similar to FADS (called the Q-ball) was used on the $X-15$ research vehicle to measure hypersonic airdata up to $M=6.7 .^{4}$ While the FADS uses a fixed orifice arrangement, the Q-ball used a moveable, ported spherical nose in a pressure-nulling concept. Experience has shown that as Mach number increases, the ambient pressure becomes much harder to obtain. The FADS will be used for future high Mach number flight applications such as the Pegasus ${ }^{\circledR}$ program.

Flight research vehicles are typically equipped with a commercial airborne thermometer that provides a measure of total (or stagnation) temperature. With this measurement, it is possible to compute airspeed as a derived parameter if accurate Mach number is available. Figure 3 shows a total temperature sensor. The accurate measure of total temperature becomes increasingly difficult as Mach number increases. Conduction-related errors in temperature sensors propagate as the first power of the temperature difference, while radiation errors propagate as the fourth power. One or more radiation shields are often used to reduce the radiation errots particularly for sensors designed for hightemperature measurements.

\section{RECENT TEST RESULTS OF OPTICAL SYSTEMS}

The systems used in the flight-test programs described here were designed to evaluate and demonstrate new airdata measurement concepts. For this reason, the hardware comprising each system was substantially larger than would be the case for an operational system for a high-performance aircraft.

\section{DOPPLER AIRSPEED SENSOR}

DOPPLER AIRSPEED SENSOR FLIGHT TEST A Doppler airspeed sensor system was tested on an F-16 aircraft. ${ }^{5}$ The purpose of the test was to @Pegasus is a registered trademark of Orbital Sciences Corp., Fairfax, Virginia. 
demonstrate and evaluate a Doppler airspeed measurement system under actual flight operational conditions and to compare with system performance predictions. The flight envelope extended up to $15200-\mathrm{m}$ altitude with flight velocities up to 283 $\mathrm{m} / \mathrm{sec}$. Angle of attack ranged from -10 to $+16^{\circ}$ and angle of sideslip covered the range from -10 to $+10^{\circ}$. A variety of atmospheric weather conditions was encountered, ranging from clear air through light rain. The system was tested on 18 flights in the Doppler velocimeter test program. The aircraft airdata system was used as the airspeed reference for the tests, although this information was not corrected (calibrated) for systematic errors such as upwash, sidewash, or static position errors that are a function of flow angle and Mach number.

DOPPLER AIRSPEED SENSOR SYSTEM DESCRIPTION A small percentage of a laser light beam directed through a particulate-rich region is reflected (scattered) back to the light source. The light backscattered from a beam of laser light has a frequency that is Doppler shifted from the transmitted frequency by an amount directly proportional to the relative velocity between the laser transmitter and the surrounding atmosphere. Figure 6 shows the Doppler velocimeter concept in operation.

A carbon dioxide laser was split into three component beams to provide the particle illumination. The laser operated at a wavelength of $10.59 \mu_{m}$ in a contınuous wave mode. The backscattered signals were mixed with the respective transmitted signals in three interferometers to generate the Doppler information. This information was then detected by the cryogenically cooled detectors. The detector outputs were analyzed in surface acoustic wave analyzers that transformed the signal into a frequency spectrum. One hundred twenty-eight different signal spectra were averaged to select the strongest backscattered frequency for further analysis. Digital processing of the spectral signals transformed the velocity components along the three beams into resolved components suitable for calculating angle of attack and angle of sideslip. Data were provided 64 times per second for each output parameter. The three beams were projected forward and downward and focused at a standoff distance of $20 \mathrm{~m}$ from the aircraft (well into the freestream). The system was housed in an envelope identical with the standard $F$. 16 centerline tank as shown in Fig. 7. The system occupied a volume of approximately $.26 \mathrm{~m}^{3}$.

DOPPLER SYSTEM SENSOR PERFORMANCE AND CONCLUSIONS Figures 8 and 9 show typical test results for low flight altitudes. As indicated in Fig. 8, excellent agreement was obtained between airspeed measurements derived from the Doppler sensor and the aircraft pressure-based system. The Doppler airspeed sensor has a frequency response that extends beyond that of the pressure-based system. The details of the differences between the systems may be the result of small gusts not visible in the pressure-based system response. Angle-ofattack reference measurements were obtained from

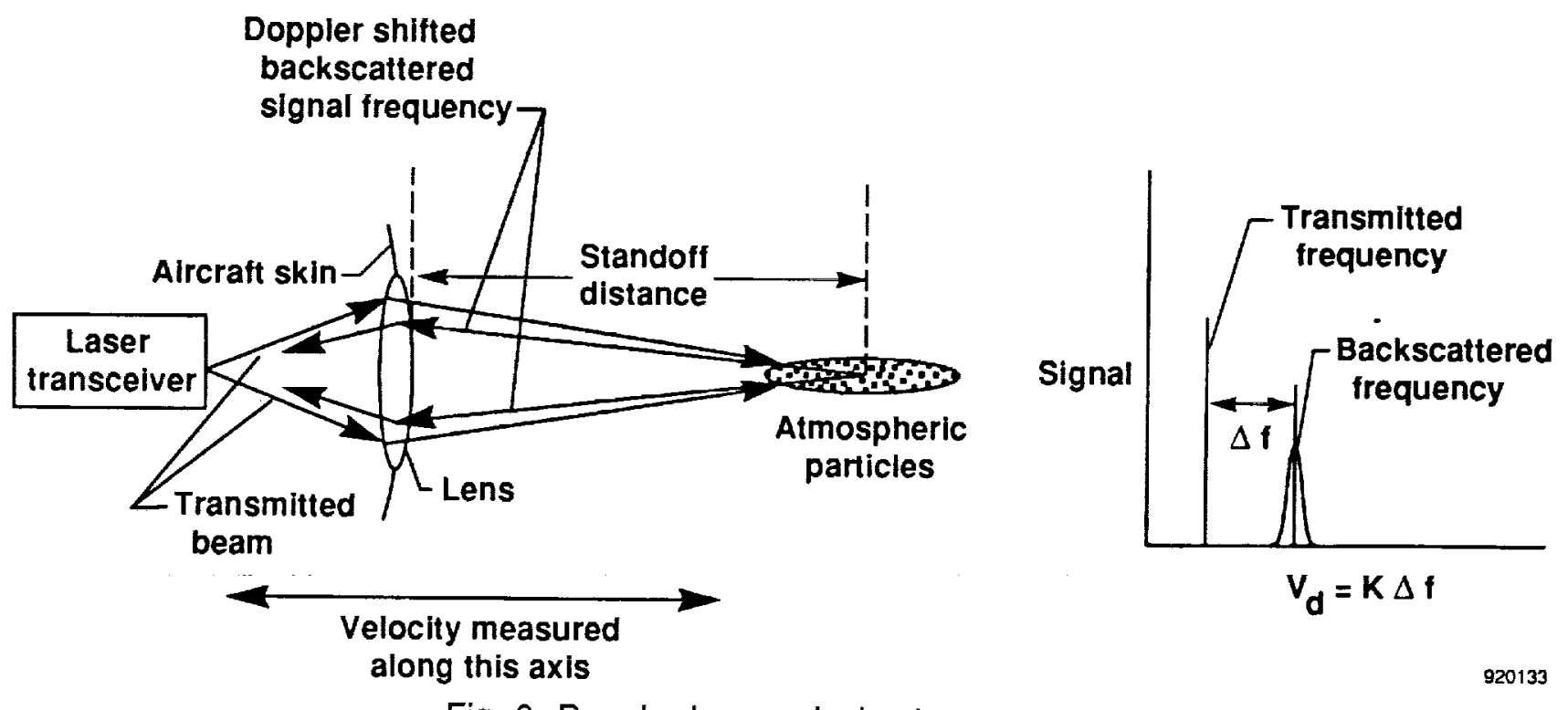

Fig. 6 Doppler laser velocimeter concept. 


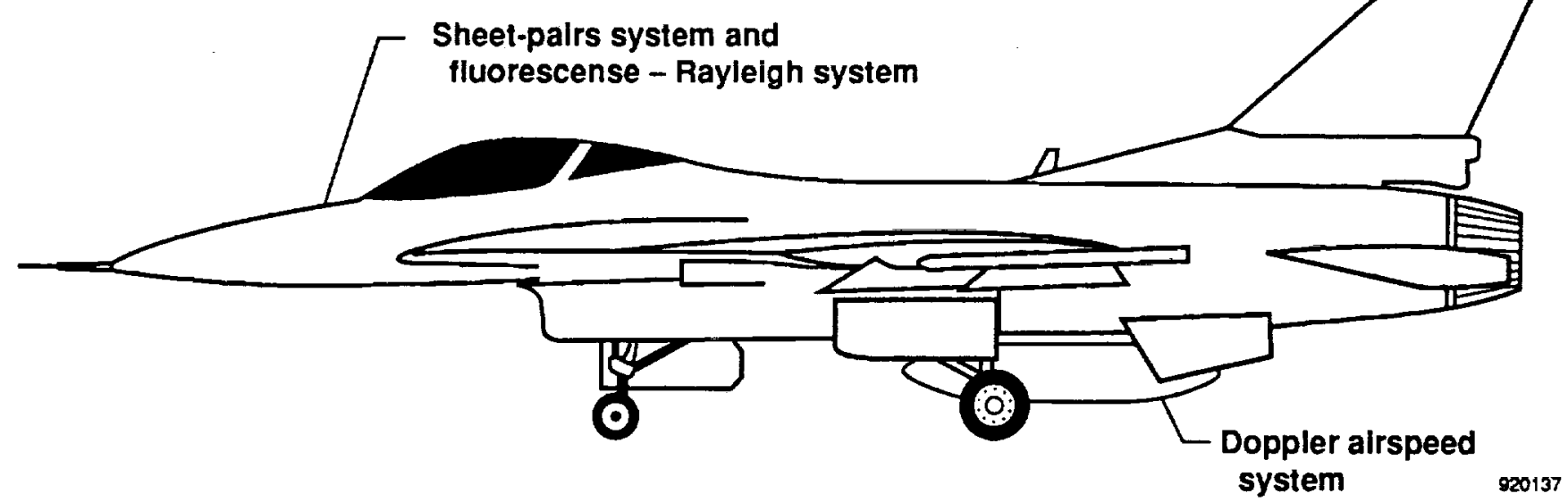

Fig. 7 F-16 Doppler velocimeter and sheet-pairs velocimeter installation.

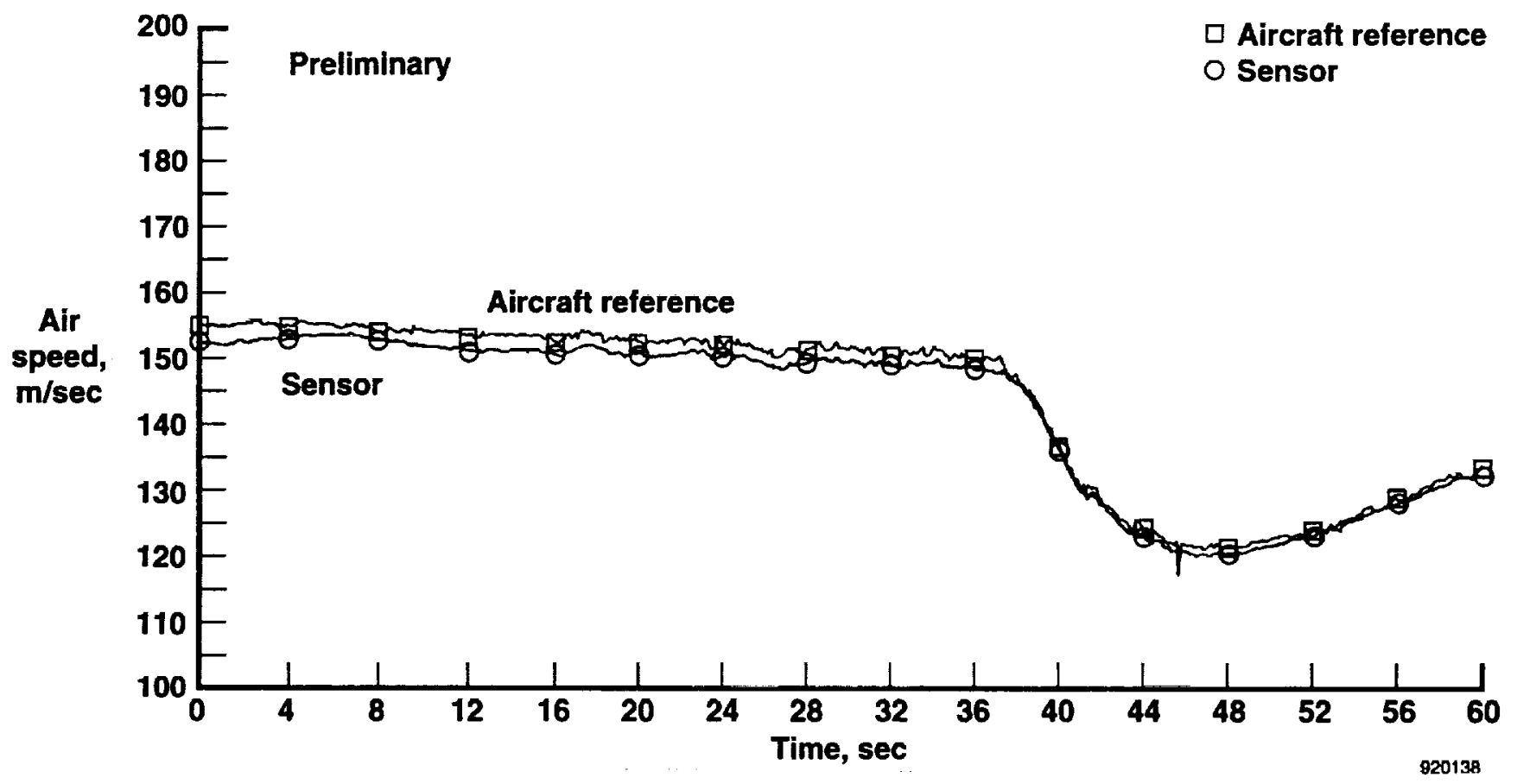

Fig. 8 Typical Doppler airspeed data from flight test.

an airdata boom and as indicated in Fig. 9, excellent agreement was also obtained between this reference and the sensor. As noted earlier, small differences may be the result of dissimilar system frequency response. The aircraft reference data is uncalibrated and a substantial part of the data offset may be the result of systematic errors in the F-16 reference systems.

The data analyzed represent $633 \mathrm{~min}$ of flight time ranging in altitude from sea level to $12200 \mathrm{~m}$. Of this total, $258 \mathrm{~min}$ (41 percent) was classified as good. Figure 10 summarizes the performance of the Doppler velocimeter sensor relative to the operating altitude. Operation was "good" (solid horizontal bars) when all three channels were locked on to aerosol signals or "partial" (partially shaded horizontal bars) when only one or two channels were providing reliable data. System operation showed substantially improved performance at lower altitudes. Evidence shows that sufficient particle availability at an appropriate size and number density contributed to satisfactory system operation. The presence of light cirrus clouds between 7900 and $12200 \mathrm{~m}$ allowed intermittent operation in this 


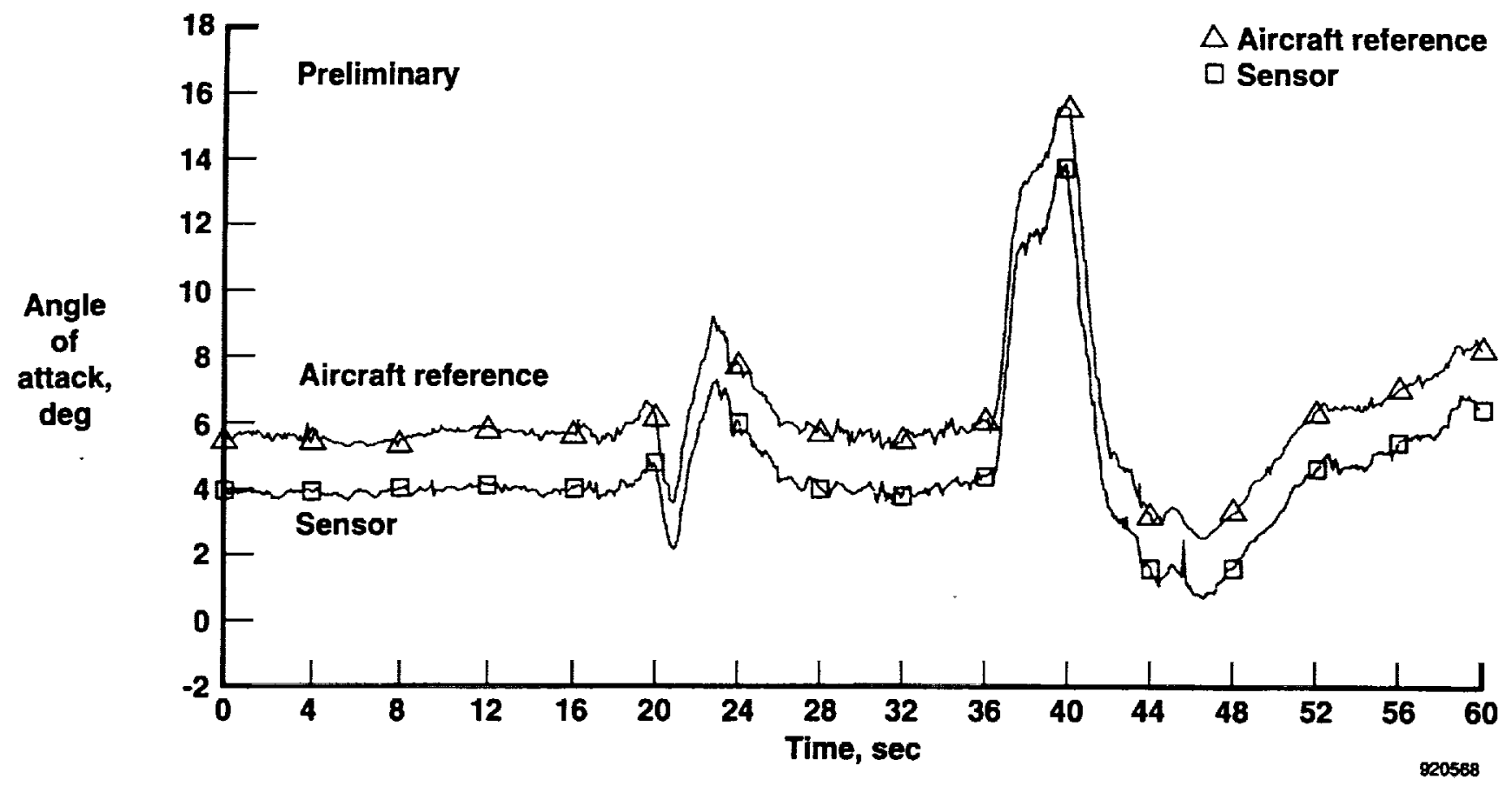

Fig. 9 Typical Doppler angle-of-attack data from flight test.

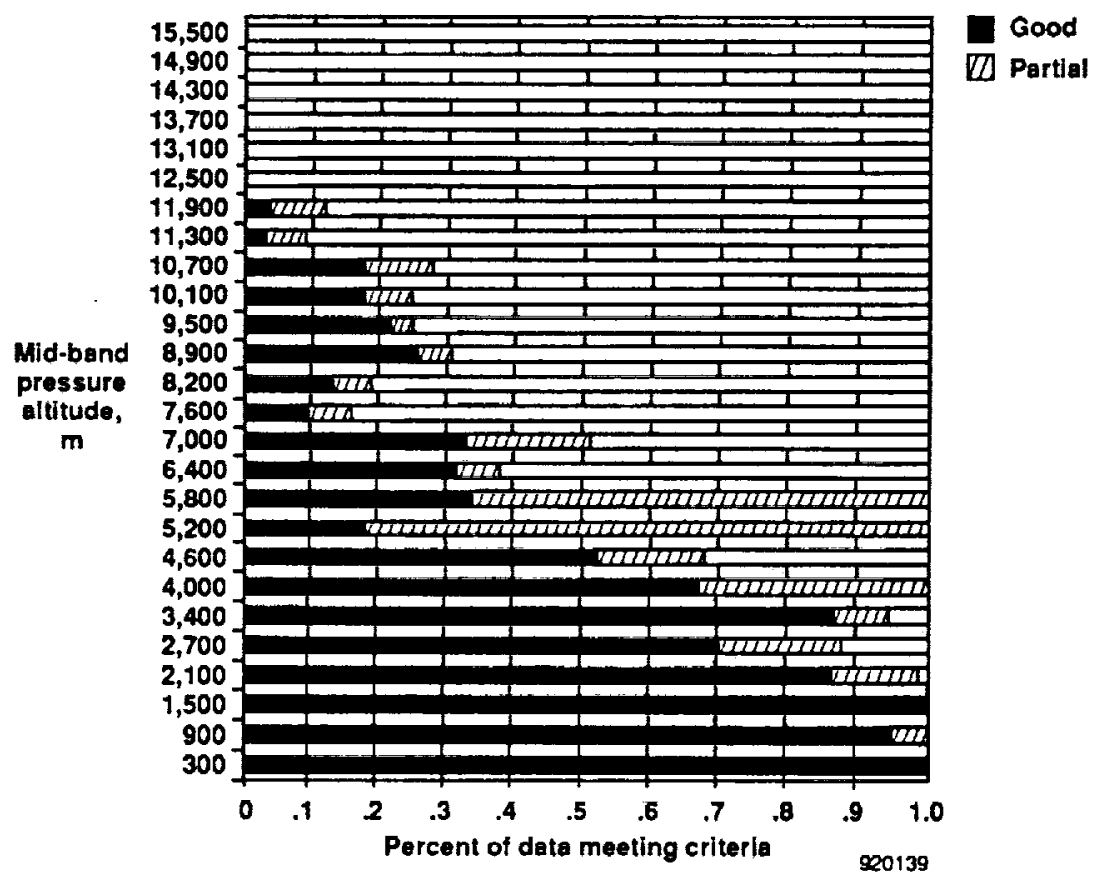

Fig. 10 Doppler velocimeter altitude performance histogram.

region of the flight envelope. The system performed well (better than in clear air) in inclement weather conditions ranging up to and including light rainfall. The largest limitation is the inability of the system to operate reliably with the existing natural density of particles at certain altitudes of the flight envelope.
The system accuracy over the range of good operation was respectable. The $1-\sigma$ standard deviation of the difference between aircraft reference and optical data sources is summarized as follows. 
Angle of attack, angle

of sideslip, deg

0.2

0.41

0.6

Airspeed, $\mathrm{m} / \mathrm{sec}$

The conclusions from the $\mathrm{CO}_{2}$ laser-based Doppler airspeed system testing can be summarized as follows:

1. A three-axis $\mathrm{CO}_{2}$ laser-based Doppler airspeed system can sustain operation in a highperformance fighter aircraft under a range of clear and inclement weather conditions. The prototype system demonstrated satisfactory operation on 14 of 18 flights in the program. System performance improved in inclement weather conditions and no special window or system component treatment is required to assure performance in these situations.

2. The correlation is consistent between pneumatic-based airspeed measurements and Doppler airspeed system measurements throughout the observed flight envelope over the region where solid returns were obtained from all three velocity axes. This result, while qualified, is encouraging and suggests that the Doppler airspeed measurement concept is technically sound. It suggests that the system may be used for calibration of conventional favorable atmospheric conditions. New optimized system designs using particle measuring wavelengths more sensitive to the small particles found at high altitudes and in clear atmospheric conditions may well cover the entire flight envelope.

\section{SHEET-PAIRS AIRSPEED SENSOR}

SHEET-PAIRS SENSOR FLIGHT TESTS The sheet-pairs airspeed sensor was flight tested in a NASA F-104 aircraft to evaluate system performance over a flight envelope extending to above $18300-\mathrm{m}$ altitude and $M=2(586 \mathrm{~m} / \mathrm{sec})$. The sheet-pairs demonstrator system had been originally built for and was tested in an F-16 aircraft up to altitudes of $15200 \mathrm{~m}$ and Mach numbers near 1.2 under a variety of atmospheric conditions. ${ }^{6}$ System performance at higher altitudes was needed as well as operation at higher airspeeds to uncover any unexpected anomalies resulting from the natural environment or from inherent system limitations. Atmospheric conditions encountered during the NASA F-104 flight test were mostly clear air conditions but included occasional light cirrus clouds. Some data were obtained from each of 16 flights flown during the program. A highly calibrated airdata system on the F-104 was used as a reference for this series of tests. The system provided outputs of true airspeed, true angle of attack, and true angle of sideslip.

SHEET-PAIRS SYSTEM DESCRIPTION The sheet-pairs airspeed system measures the time required for a particle to traverse the distance between two highly focused sheets of light to determine the
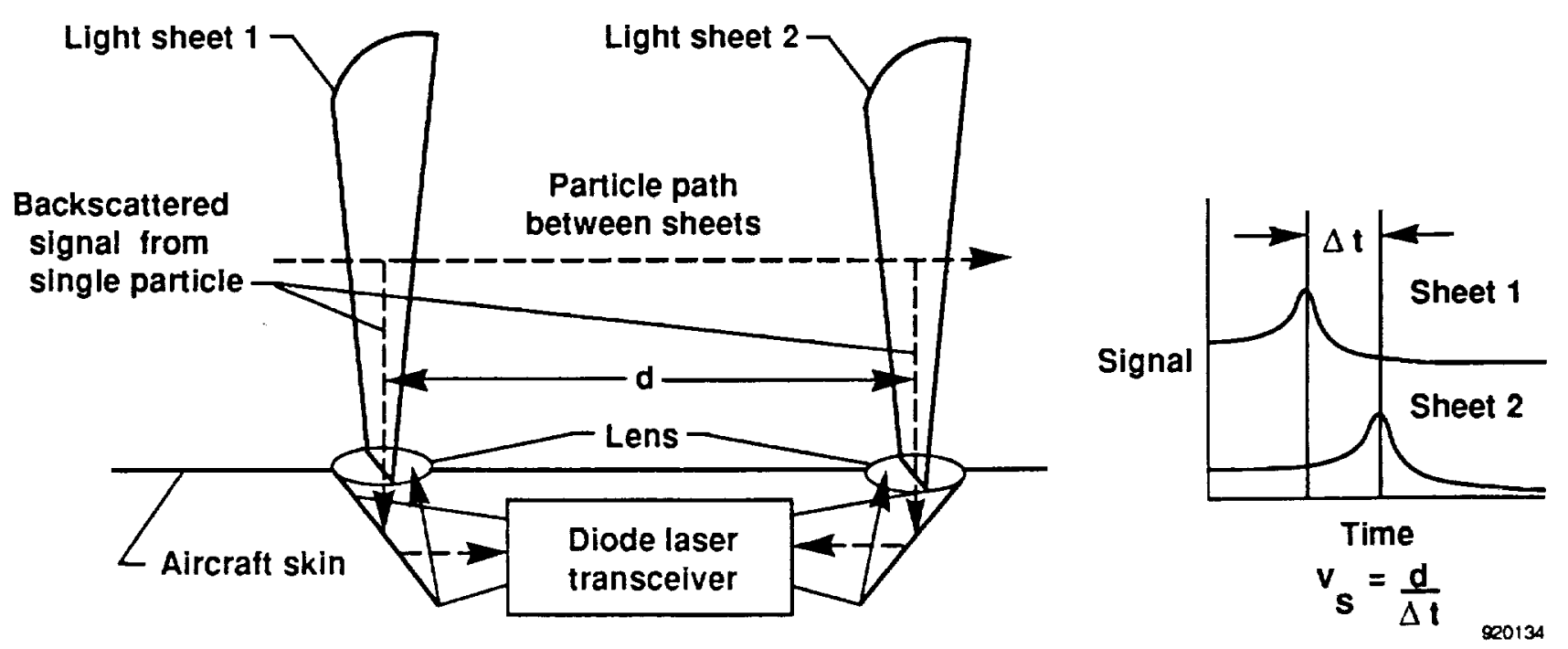

Fig. 11 Sheet-pairs time-of-flight concept. 
particle velocity. Additional sensing planes of light oriented perpendicular to the original set of planes permit the measurement of the three-dimensional velocity vector. Figure 11 shows the sheet-pairs system concept.

Lasers at a wavelength of $.810 \mu_{m}$ were used and were configured to measure particle passing velocity at a point approximately $1.2 \mathrm{~m}$ from the aircraft surface which is still inside the local flow field for most flight vehicles. A set of three sheet-pairs systems is required to measure airspeed in three different (nonorthogonal) directions to obtain the magnitude and direction of the airspeed vector. One sheet pair was oriented to measure the airspeed component nearly parallel to the aircraft longitudinal $(x)$ axis. The other two sheet pairs were arranged to measure vertical and side velocities. The angle-ofattack and angle-of-sideslip flow angles were calculated from the vertical and side components of velocities obtained from the other two sheet pairs. Figure 12 shows the F-104 installation. The sheet pairs are separated by $1 \mathrm{~cm}$ as presently configured. The system occupied a volume of approximately $0.1 \mathrm{~m}^{3}$. Data were updated 50 times per second for each output parameter.

The complexity of the backscattered signal from the light sheets requires signal discrimination to derive accurate time-of-flight estimates. Optical spatial and spectral filtering limit the extraneous light permitted inside the detectors. Automatic gain control maintains the sensitivity to particle events approximately constant over the flight envelope. Adaptive threshold adjustment controls the rate of particle everit occurrence to match the computational speed of the system and provide the best statistical basis for estimating time-of-flight duration. High-speed digital processing discriminates between noise and real particle events for the subsequent correlation process to match events between the sheet pairs. Figure 13 shows the inferred particle size distribution measured on one flight of the F-104. Particle size distribution was inferred from the individual particle backscattered signal strength. The system uses the strongest backscattered signals available to gather the data set for each measurement. This approach rejects weaker backscattered signals and therefore under-reports smaller particles when the supply of larger particles is adequate. This test was performed shortly before the eruption of the Mt. Pinatubo volcano in the Philippine Islands, so the results show that sufficient particles existed prior to the assumed particle enrichment resulting from this volcanic eruption.

SHEET-PAIRS SYSTEM PERFORMANCE AND CONCLUSIONS The flight test was conducted during the summer season and the equipment was subjected to hot environmental conditions beyond the design specifications. This hot environment may have induced premature failures in one or more of the sheet-pair velocity component axes. For this reason, there were only intermittent data obtained from the side velocity pairs and therefore, limited angle of attack or angle of sideslip data available for analysis. Fortunately, the $x$-axis sheet pair was the most reliable and most of the flight data were obtained from this axis. Figure 14 shows the $x$-axis data obtained from the flight test and Fig. 15 shows the reference correlation.

There are several conclusions that can be drawn from the flight-test results. These conclusions can be categorized into those associated with the system performance and those related to the natural atmospheric environment that can be implied from the system response to that environment. Except for the conclusion about the natural environment, most of the other conclusions should be considered preliminary, as further system performance assessment is underway and new insights are expected as the result of this activity.

The natural particulate sizes and concentrations were sufficient at the time of these tests for satisfactory system operation up to $18300-m$ altitude under night flight conditions. That is not to say that this situation would be true for all occasions at the test site or at all global locations. It is expected that system signal-to-noise ratios will be improved to permit more robust operation at $18300 \mathrm{~m}$ and to operate at higher altitudes.

The remaining conclusions are related to the system performance characteristics and are as follows:

1. The correlation between pneumatic-based airspeed measurements and sheet-pairs system measurements is reasonably consistent throughout the observed flight envelope. There were some minor velocity measurement anomalies at the higher airspeeds, the source of which is uncertain. Since the variations appear to be repeatable and are found at 


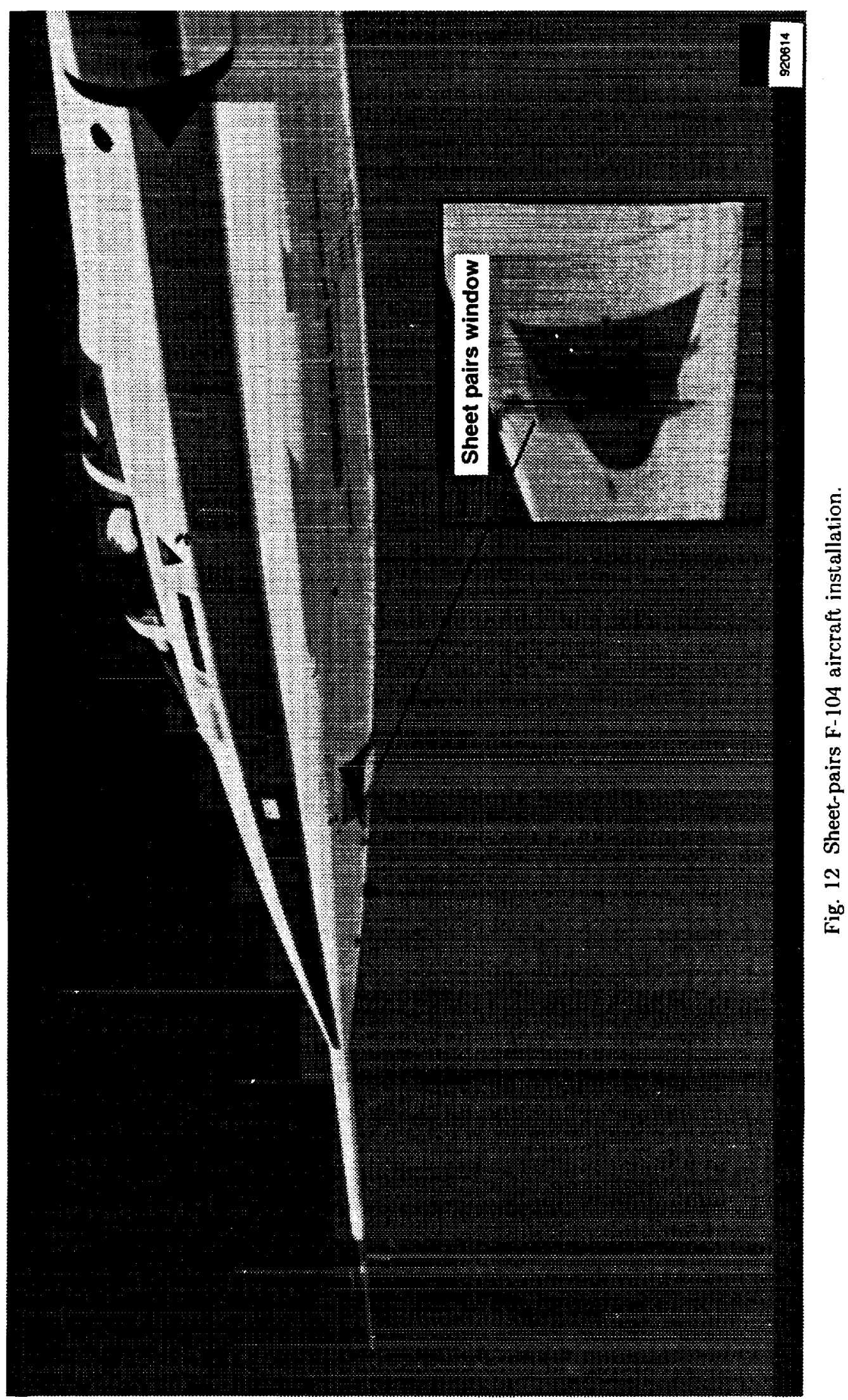




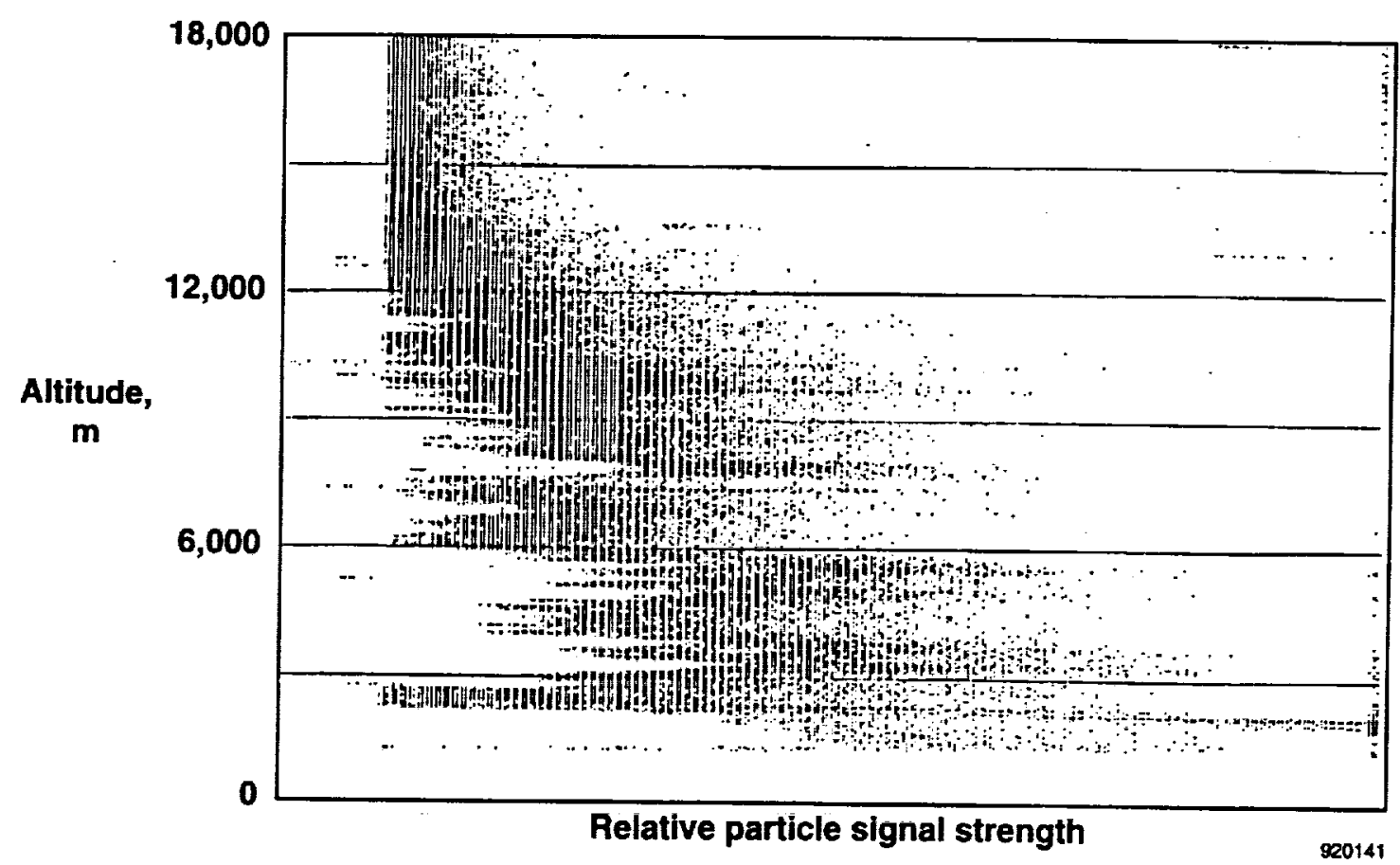

Fig. 13 Particle backscattered signal strength as a function of altitude.

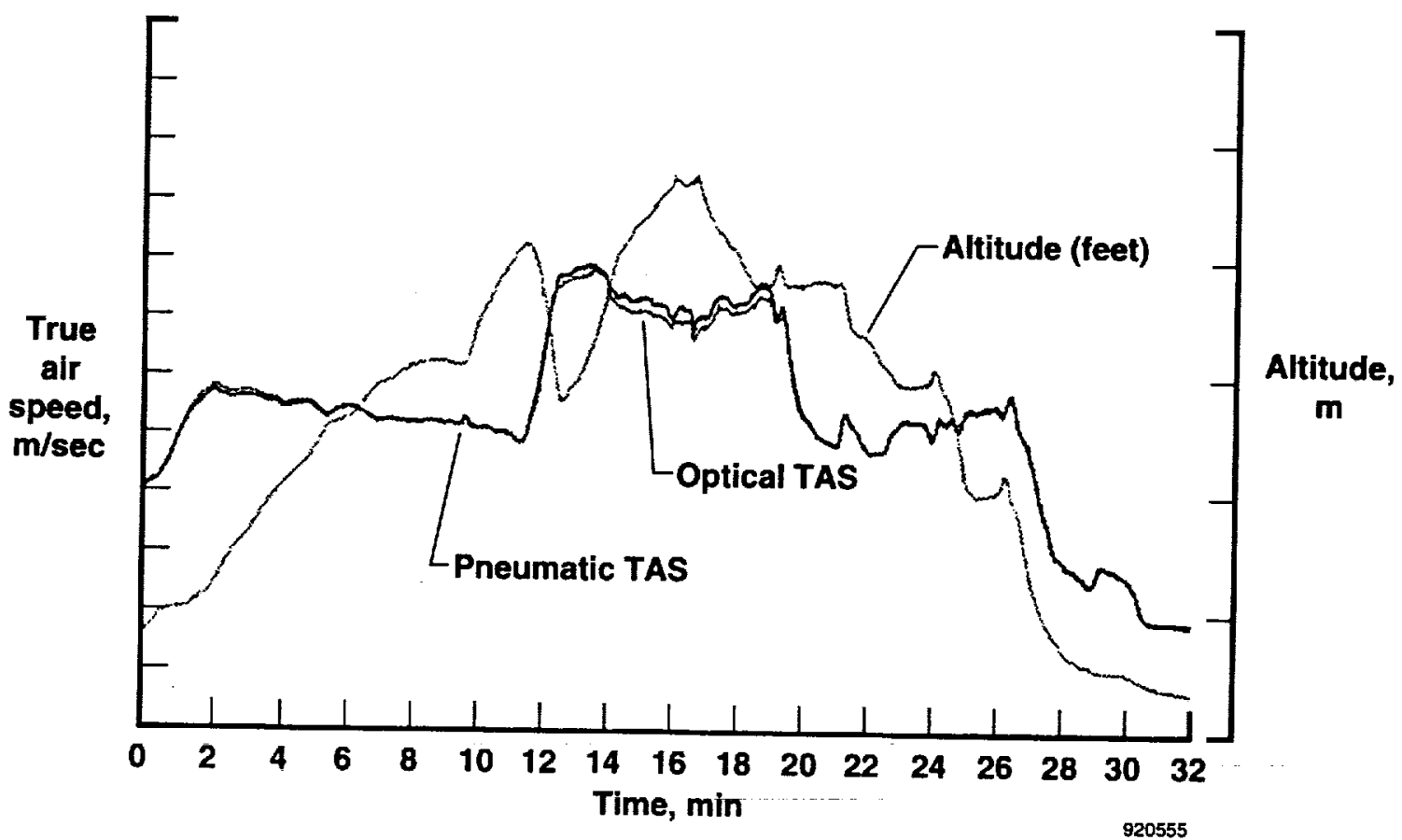

Fig. 14 Typical sheet-pairs velocimeter test results. 


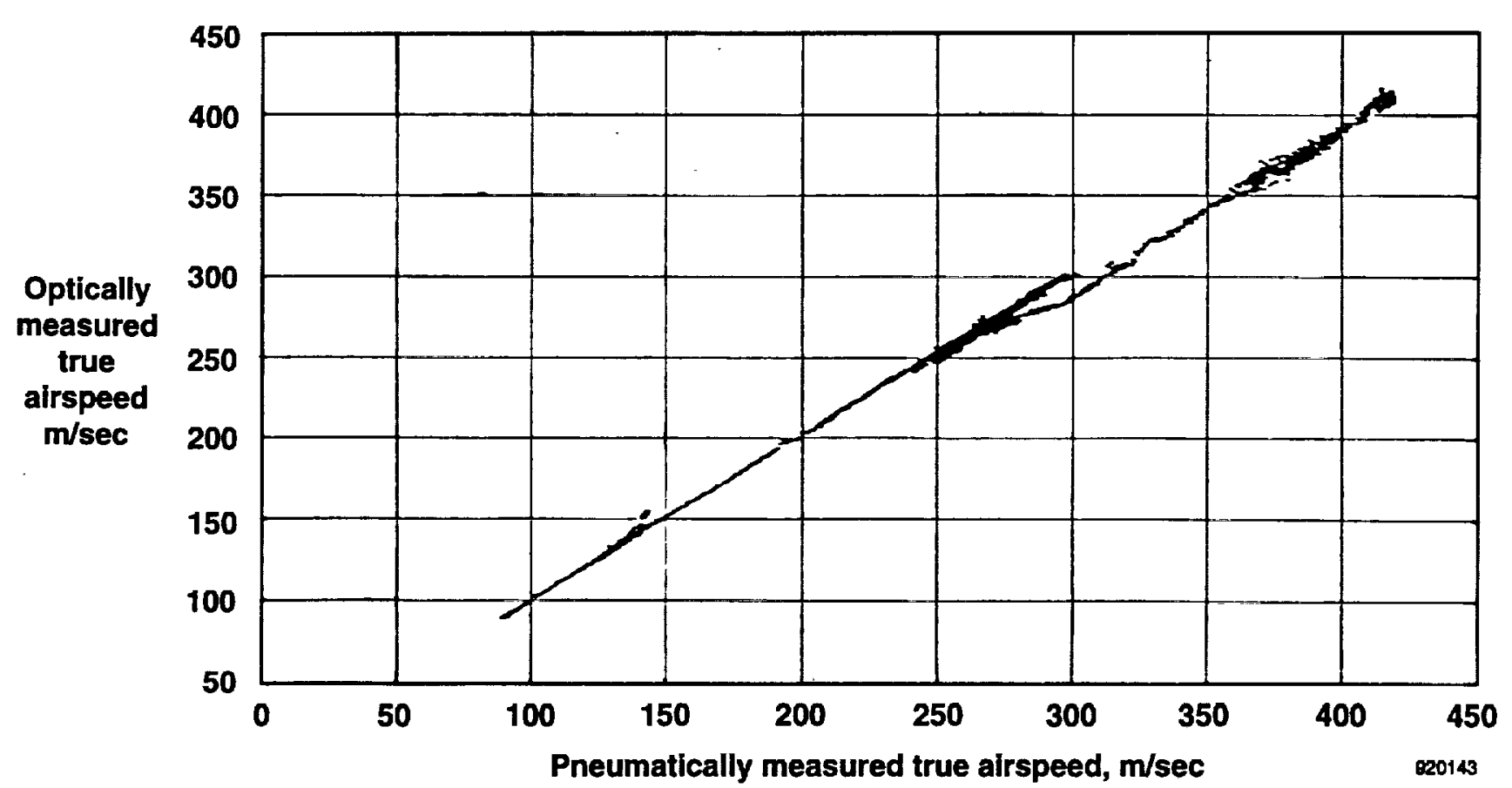

Fig. 15 Typical sheet-pairs velocity measurement correlation.

supersonic flight conditions, the source is most likely a series of shock-induced flow disturbances near the sheet-pair measurement region. Recent data assessment suggests that a system software change may reduce the data scatter at these flight conditions. Figure 15 shows the correlation with the reference velocity.

2. The system can characterize the atmospheric aerosol environment. The intensity of backscattered light from aerosols varies with wavelength, particle size, particle shape, and particle material index of refraction, but is a strong function of particle size. The system shows promise for measuring the particle environment with proper calibration to relate the measured backscattered intensity to particle size. An advantage over existing particle measurement techniques is the improved high particle sample rate capability (as much as three orders of magnitude beyond current samplers). Current samplers have very low frequency response and are of limited use for characterizing the fine structure of atmospheric particulate concentrations from highspeed aircraft.
3. The background lighting conditions strongly influence the system performance. The downward-looking installation in the F-104 caused the background (for normal flight conditions) to be the bright desert floor characteristic of the area around the Dryden facility. This bright background reduced the particle contrast. Inverted flight (where the dark sky became the background) and night flight improved system performance. These results suggest that background control through filtering or other techniques will enhance system performance.

The results of the sheet-pairs sensor flight test on the F-104 clearly show that this measurement concept has promising potential for measuring vehicle airspeed at ranges of about $1 \mathrm{~m}$ from the surface of the flight vehicle. Further flight testing and results assessment will suggest avenues for system modifications to improve performance substantially under a broader range of flight conditions. It may be possible to extend the distance of the measurement volume from the surface of the flight vehicle to reduce the local flow field effects. 


\section{FLUORESCENCE AND RAYLEIGH SCATTER SENSOR}

FLUORESCENCE AND RAYLEIGH SCATTERBASED AMBIENT TEMPERATURE AND DENSITY SENSOR FLIGHT TESTS Ultraviolet molecular backscatter and oxygen fluorescence have been used to measure atmospheric density and temperature to altitudes of $15200 \mathrm{~m}$ during an F-16 flight test. $^{7}$ Figure 7 shows the installation location on the F-16. The system acquired flight data by using a flash lamp instead of the more desirable laser source. The results from the oxygen fluorescence would be of much higher quality with a narrow-band laser excitation, but size and power limitations of the aircraft made the high-power laser impractical. The flight tests were conducted to demonstrate and assess the performance of the sensing concept under several ambient lighting conditions (including night illumination). Eighteen flights were conducted during the program.

FLUORESCENCE AND RAYLEIGH SCATTER SENSOR DESCRIPTION Results from laboratory experiments with high-power lasers have suggested a concept for obtaining freestream density and temperature using laser-induced fluorescence and Rayleigh scattering techniques. Air density can be inferred from ultraviolet light backscattered from molecules, or from the strength of fluorescence radiation from excited molecules. Static air temperature is available through the analysis of fluorescence from oxygen molecules, which defines the energy state populations that vary with the temperature of the oxygen molecule. A broad-band ultraviolet flash lamp was used in the sensor to project ultraviolet energy into a probe volume. A sensor channel measures the flash lamp intensity so that any pulse-to-pulse variation of the lamp output may be normalized. Several dichroic mirrors were used to confine the spectral output within the .185to $.200-\mu_{m}$ range. Two separate detector channels collect the scattered light from the probe area. One channel observes the Rayleigh scattering in the band of the flash lamp source. Rayleigh scattering is proportional to the number density of the air molecules (and any scattering from particulates in the probe region). The second channel measures the oxygen molecule fluorescence between .220 and $.280 \mu_{m}$. This measurement is a function of the temperature and the oxygen molecule number density. These two channels provide two measurements for the two unknown ambient air parameters. One channel extracts density; the second measures combined temperature and density from which density dependence is separated, leaving the temperature. The measurement volume extended to about $3 \mathrm{~m}$ from the aircraft and the probe volume diameter was approximately $.5 \mathrm{~m}$. The sensor occupled about $0.034 \mathrm{~m}^{3}$ and data updates were provided at 100 per second.

FLUORESCENCE AND RAYLEIGH SCATTER SENSOR PERFORMANCE AND CONCLUSIONS The use of spectral diagnostic techniques in flight applications is at the proof of concept stage of development where demonstrating the relationship between the variables is of prime concern. The flight test included several maneuvers and encounters with atmospheric phenomena, which provided opportunities to observe large variations in either temperature or number density. These situations included rapid climbs and dives, encounters with jet wake turbulence, and flight through weather patterns such as heavy turbulence and cloud formations. Figures 16 and 17 show data obtained during rapid climb and dive maneuvers presented with number density and temperature baseline information to illustrate the correlation.

The correlation between the number density and the fluorescence signal shown in Fig. 16 shows promise for the range investigated. The data shown in this figure would not meet the accuracy or resolution requirements for use in an operational aircraft, but represent a solid beginning which, with improved technology, may lead to an operational sensor in the future. Operational aircraft derive altitude information from the accurate measurement of am. bient pressure. Density measurement may also be used to derive altitude, but the results from this test would not provide the required accuracy, repeatability, or resolution necessary for altitude determination. Using the fluorescence signal instead of the Rayleigh scattered signal will remove the sensitivity to the presence of particles in the probe volume. The zero point on the vertical scale of Fig. 16 represents the mean value of the displayed parameters over the span of time displayed in the figure.

The data shown in Fig. 17 represent more of a challenge in the measurement of temperature. Definite trends are illustrated in the data, however, a more solid relationship must be established 


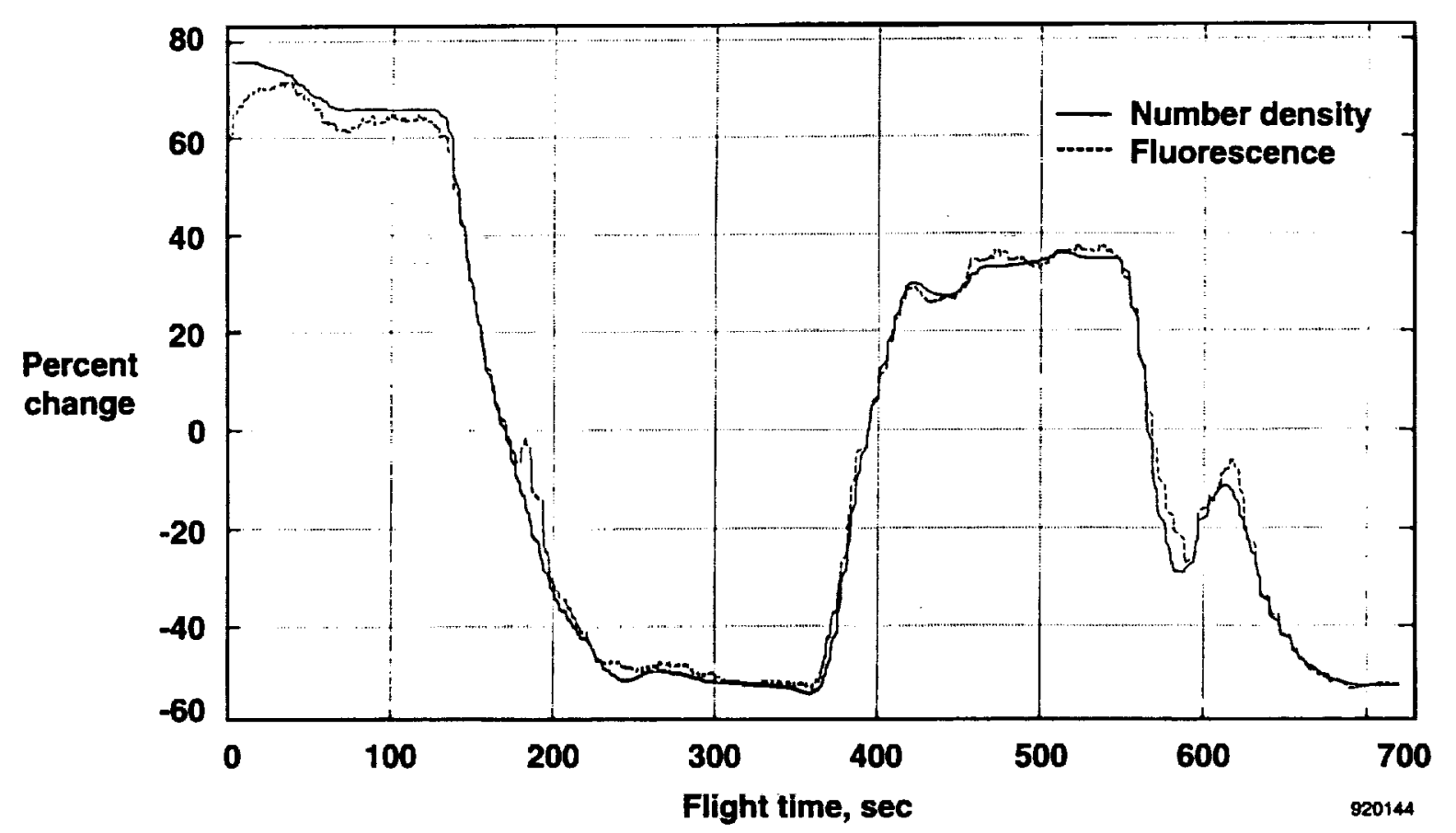

Fig. 16 Comparison of number density and fluorescence data.

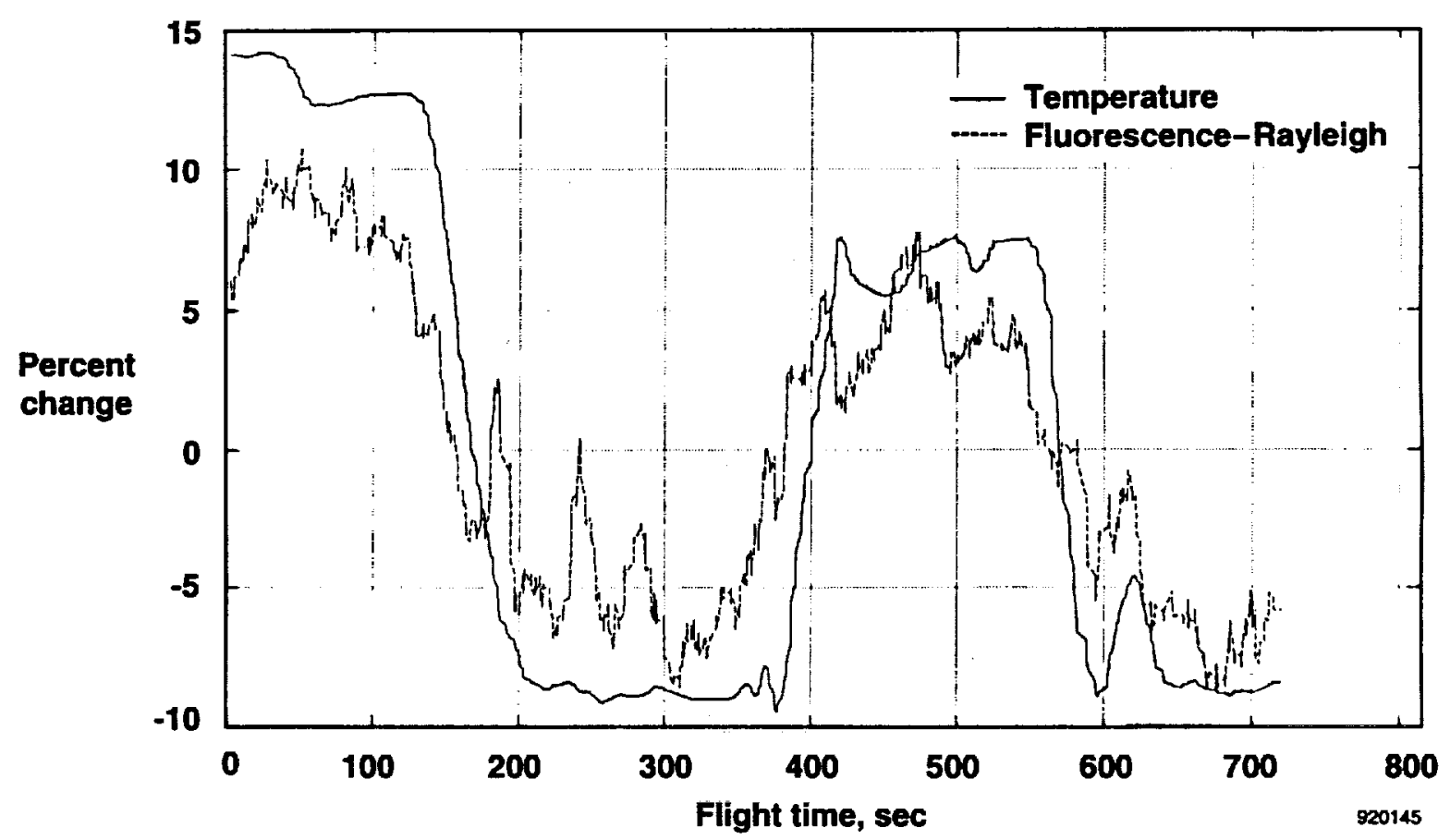

Fig. 17 Comparison of static temperature and fluorescence data.

between temperature and the fluorescenceRayleigh ratio before it can be considered a serious contender for flight temperature measurement. In all fairness, the test used a broadband excitation source and collected signals across a broad fluorescence bandwidth. Imbedded in these broad bands are many molecular interactions and the results from these tests are the accumulated responses of many processes. Laser excitation allows selection of only those processes known to be highly correlated with temperature measurement. As with Fig. 16, the zero point on the vertical scale of Fig. 17 represents the mean value of the displayed parameters over the span of time displayed in the figure. 
The conclusions from the fluorescence and Rayleigh scatter sensor testing are as follows:

1. A nonintrusive ambient condition measurement system has been demonstrated on a high-performance aircraft in flight to an altitude of $15200 \mathrm{~m}$.

2. Potential has been shown for measuring static density and temperature, however, substantial improvement in the performance is needed to make the technique suitable for widespread use. Major improvements in the accuracy, repeatability, and resolution of the density measurement will be necessary.

\section{RADIOMETRIC TEMPERATURE SENSOR}

RADIOMETRIC TEMPERATURE SENSOR FLIGHT TESTS A radiometric temperature measurement concept using the background radiation from the 4.255- $\mu_{m}$ band of atmospheric carbon dioxide allows ambient temperature to be determined nonintrusively. Figure 18 illustrates the radiometric temperature measurement concept. Narrow band radiation from the atmosphere is compared with black body radiation in the same band and a temperature feedback loop is used to match the black body radiation intensity to the atmospheric intensity. When a match is achieved, the temperature of the black body is equivalent to the temperature of the region of the atmosphere within the field of view. The 4.255- $\mu_{m}$ band is highly absomptive and the optical depth (region from which the radiation is derived) is inversely proportional to atmospheric density (about $10 \mathrm{~m}$ at low altitudes). It offers a completely passive method for obtaining true static temperature by measuring the black body temperature. The spatial resolution of the radiometric temperature sensor is limited to the optical depth.

Radiometric temperature measurement capability has been under development for several years at the National Center for Atmospheric Research (NCAR, Denver, CO) ${ }^{8}$ Accurate in-cloud temperature measurements have been difficult to acquire using conventional immersion-type sensors and the evaluation of the radiometric temperature measurement concept has been driven by the need to make the in-cloud measurements. A system was tested on an NCAR King-Air aircraft at altitudes near $2100 \mathrm{~m}$. Although the in-cloud measurements were the focus of this flight test, the performance for a variety of flight conditions was assessed. The results in the clear air situation were obtained from a data set of 3,775 independent measurements obtained in 1985 and were confirmed by a second series of tests including more than 10,000 data points collected between 1985 and 1988. Temperature measurement comparisons obtained inside cloud formations were similar to those obtained from clear air testing. The comparison standard for the radiometric thermometer was a highly calibrated immersion sensor.
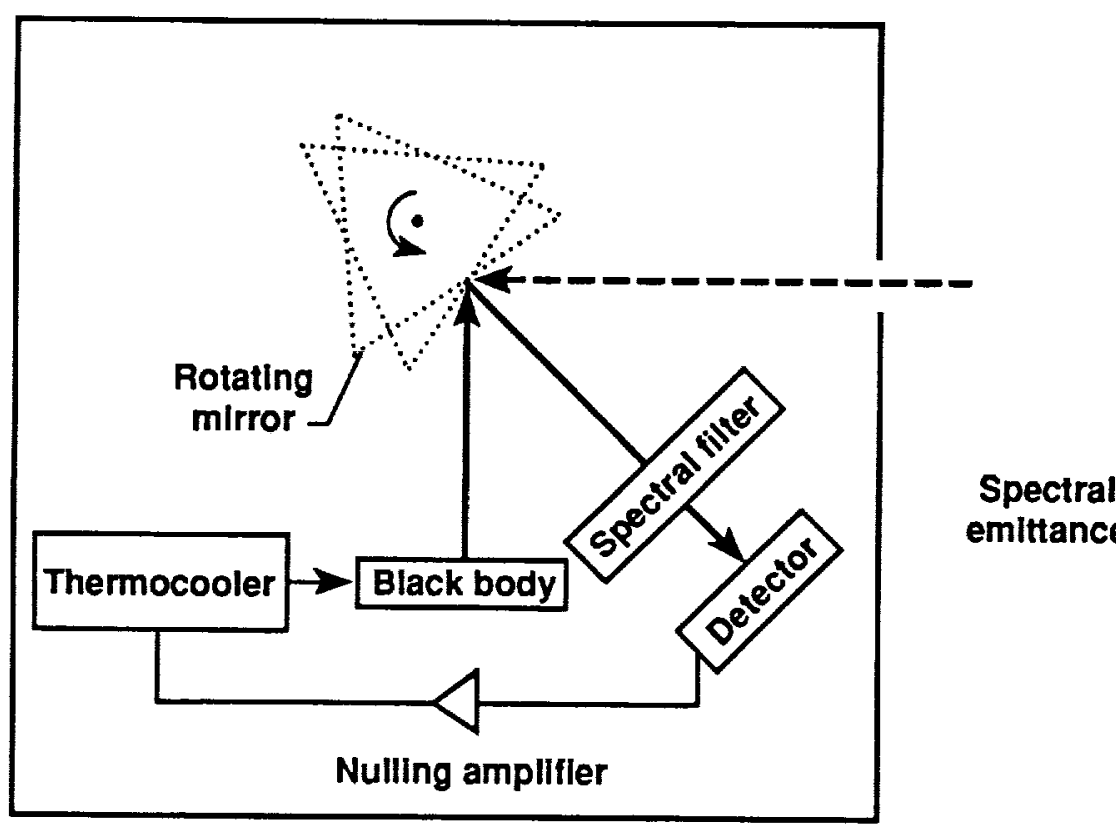

Fig. 18 Radiometric temperature measurement concept.

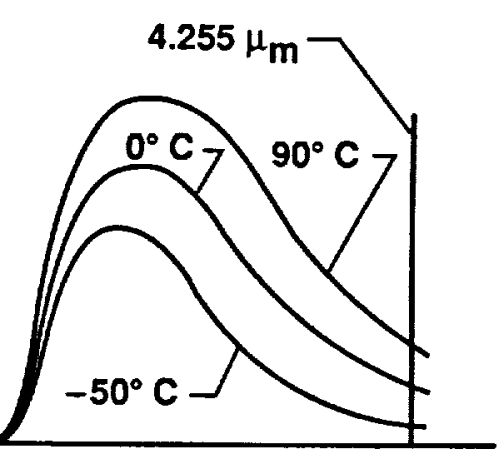

Frequency 
RADIOMETRIC TEMPERATURE SENSOR DESCRIPTION The radiometric temperature sensor measures the spectral radiance of a narrow band of $\mathrm{CO}_{2}$ to determine the corresponding temperature of the emitting gas. Because of its strong emitterabsorber characteristics, the $4.255-\mu_{m}$ wavelength was selected where $\mathrm{CO}_{2}$ experiences several molecular vibrational-rotational transitions. The average temperature of a column extending about $10 \mathrm{~m}$ (the optical depth) from the aircraft is the output from the sensor. Measurements obtained this way have several advantages; (1) unlike immersion sensors, the sensor does not disturb the air temperature, (2) no thermal relaxation time limits the frequency response, and (3) the presence of clouds does not strongly affect the reading because spectral lines of water do not overlap the $\mathrm{CO}_{2}$ line. The sensor occupled about $0.085 \mathrm{~m}^{3}$. Data updates were provided at an equivalent rate of 25 per second.

RADIOMETRIC SENSOR PERFORMANCE AND CONCLUSIONS Because the radiometric sensor and the reverse flow sensor use two different sensing techniques, matching results provides strong evidence that both techniques are valid. However, different time response characteristics make it important to filter the results properly to assure that it is really steady-state information that is being compared. Figure 19 illustrates the high correlation between the radiometric temperature sensor and the reference sensor.

The conclusions from the radiometric temperature sensor testing are quoted as follows: ${ }^{9}$

1. The radiometric sensor agrees with immersion sensors in clear air to within the estimated 1 $\sigma$ accuracy of those sensors $\left(0.3^{\circ} \mathrm{C}\right)$.

2. The radiometric sensor measures temperature more accurately in clouds than the immersion sensors. There is clear evidence that the wetting of the immersion sensors at temperatures above freezing causes evaporation and an erroneously low reading.

3. On occasion there are some apparent airspeed expansion effects that cause the radiometric sensor to measure temperatures too low by up to $0.8^{\circ} \mathrm{C}$. These effects are thought to be the result of accelerated airflow around the aircraft fuselage. Although this temperature error is larger than the error band cited previously in (1) it was only infrequently observed and was averaged with other measurements with much higher accuracy.

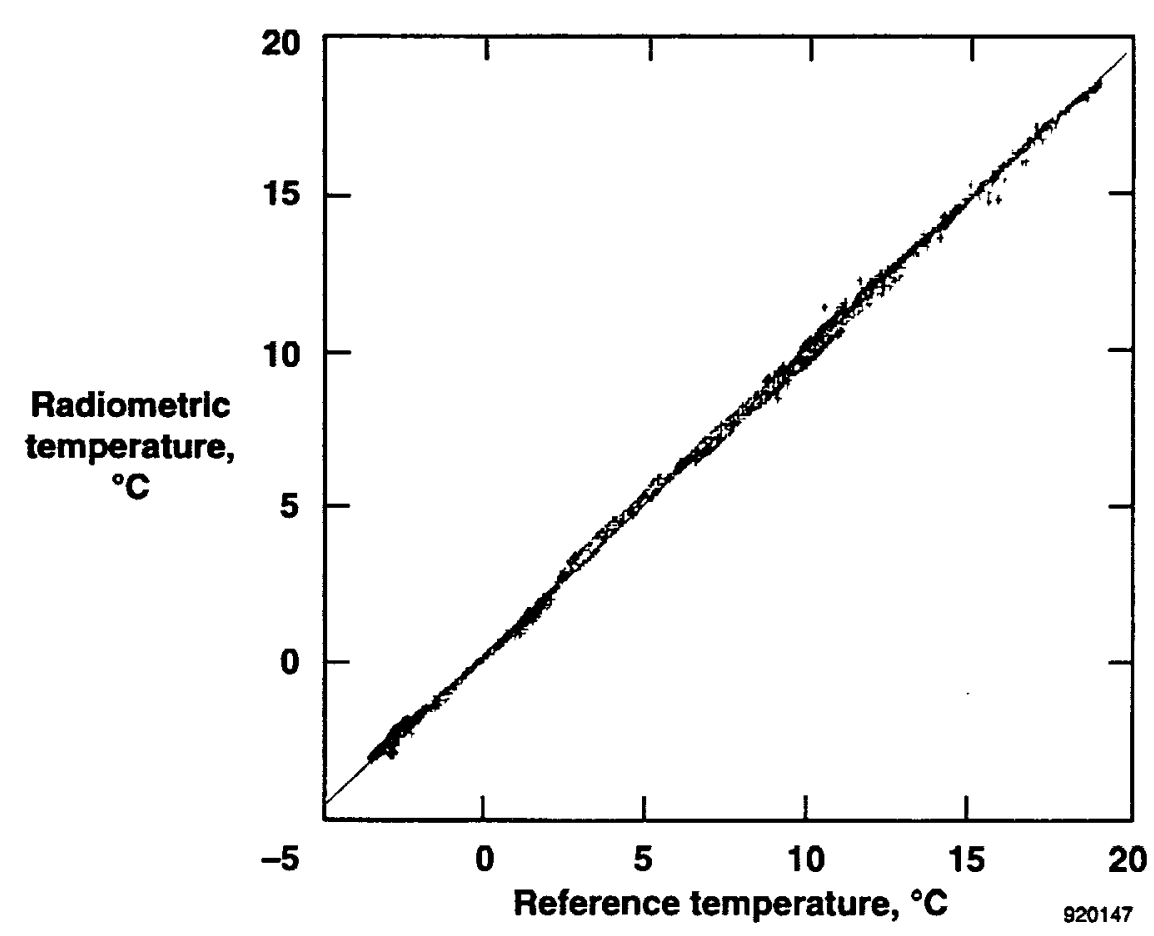

Fig. 19 Correlation of flight temperature data from radiometric and conventional sensors. 


\section{GENERAL CONCLUSIONS}

Based on the in-flight performance of the optical airdata measurement techniques reviewed, it is possible to draw the following general conclusions:

1. Optical sensors show potential in current form for specialized applications such as airspeed calibration or reliable temperature measurement in clouds.

2. Optical airdata can obtain free-stream measurements not available with existing methods.

\section{FUTURE DIRECTION}

ATMOSPHERIC CHARACTERIZATION The optical velocity measurement techniques described rely on the presence of naturally occurring particulates for operation. The present knowledge of this atmospheric particulate environment is insufficient to provide clear guidelines for optimal selection of laser wavelength and for pulse power or energy requirements. Particulate information at high spatial and temporal resolutions is needed to select the most effective system parameters.

TECHNOLOGY ADVANCEMENTS Laser technology is the most pressing issue in bringing optical airdata sensing techniques into a practical state of operation. Improvements are needed in the power output and efficiency of small lasers that can be realistically packaged into flight avionic systems. Additional work is needed to provide the proper pulse characteristics for pulsed laser systems.

\section{CONCLUDING REMARKS}

Optical techniques for measuring airdata parameters have been demonstrated in flight. These systems can measure the airspeed vector nonintrusively from the free-stream. Today's requirements for measuring airdata at high angle of attack, and tomorrow's need for measuring the same information at hypersonic flight conditions place unacceptable strains on existing techniques and clearly show that these new concepts should be evaluated for potential application in future programs. Other optical concepts for measuring freestream static temperature and density have also been demonstrated in flight. Optical technology advances show promise for making the common use of many of these optical concepts a reality in the future.

\section{NOMENCLATURE}

$d \quad$ distance between sheet pairs, $\mathrm{mm}$

FADS flush airdata sensor

$K \quad$ Doppler system scale factor $(2 \times$ wavelength), $m$

NCAR National Center for Atmospheric Research, Boulder, CO

$P s \quad$ airdata boom static pressure, $\mathrm{Pa}$

Pt

$V_{u, v, w}$ airdata boom total pressure, $\mathrm{Pa}$ Doppler measured airspeed corresponding to $x, y, z$ body axis referenced airspeed components, $\mathrm{m} / \mathrm{sec}$

$V_{S} \quad$ sheet-pair measured airspeed, $\mathrm{m} / \mathrm{sec}$

$V_{T} \quad$ total Doppler derived airspeed, $\mathrm{m} / \mathrm{sec}$

$\alpha \quad$ angle of attack, deg

$\beta \quad$ angle of sideslip, deg

$\Delta f \quad$ Doppler frequency shift, $\mathrm{Hz}$

$\Delta t \quad$ time-of-flight for sheet-pairs system, sec

$\mu_{m} \quad$ micron $\left(10^{-6}\right.$ meters $)$

\section{REFERENCES}

${ }^{1}$ Anderson, John D., "Modern Compressible Flow," McGraw-Hill Publishing Co., 1990.

${ }^{2}$ Haering, Edward A., Airdata Calibration of a High-Performance Aircraft for Measuring Atmospheric Wind Profiles, NASA TM-101714, 1990.

${ }^{3}$ Moes, Timothy R. and Stephen A. Whitmore, $A$ Preliminary Look at Techniques Used to Obtain Airdata From Flight at High Angles of Attack, NASA TM-101729, 1990.

${ }^{4}$ Wolowicz, Chester M. and Terrence D. Gossett, Operational and Performance Characteristics of the $X-15$ Spherical Hypersonic Flow-Direction Sensor, NASA TN D-3070, 1965.

${ }^{5}$ Silverman, B.B. and L.A. Newman, "Flight Testing of a Three-Axis $\mathrm{CO}_{2}$ Laser Doppler Velocimeter," United Technologies Optical Systems, Inc., West Palm Beach, FL, Feb. 1990.

${ }^{6}$ Smart, Anthony E. and John B. Abbiss, "NASA F-104 Flight Testing of the Titan Spectron Optical Air Data Sensor (OADS) System," Titan Spectron Report Number 91-2877-24, Sept. 1991.

${ }^{7}$ Azzazy, Medhat, John B. Abbiss, and Robert W.McCullough, "Determination of Aircraft Pressure 
Altitude and Ambient Temperature Using Fluores" cence and Rayleigh Scattered Radiation from a Continuum Source," SPECTRON Development Laboratories, Costa Mesa, CA. Presented at the NATO Advanced Study Institute, Algarve, Portugal, Apr. 1990.

${ }^{8}$ Lawson, R. Paul and William A. Cooper, "Performance of Some Airborne Thermometers in
Clouds," J. of Atmospheric and Oceanic Technology, Vol. 7, No. 3, July 1989.

${ }^{9}$ Cooper, William A., "The Ophir Radiometric Thermometer: Preliminary Evaluation," National Center for Atmospheric Research, NCAR TN-292 + STR, June 1987. 
\begin{tabular}{|l|l|l}
\hline 1. AGENCY USE ONLY (Leave blank) & $\begin{array}{l}\text { 2. REPORT DATE } \\
\text { May } 1993\end{array}$ & $\begin{array}{l}\text { 3. REPORT TYPE AND DATES COVERED } \\
\text { Technical Memorandum }\end{array}$
\end{tabular}

4. TITLE AND SUBTITLE

5. FUNDING NUMEERS

Recent Flight-Test Results of Optical Airdata Techniques

6. AUTHOR(S)

RTOP 505-68-50

Rodney K. Bogue

7. PERFoRMING ORgANIZATION NAME(S) AND ADDRESS(ES)

NASA Dryden Flight Research Facility

P.O. Box 273

TING ORGANIZATION REPORT NUMBEA

Edwards, California 93523-0273

H-1915

9. SPONSORING/MONITORING AGENCY NAME(S) AND ADDRESS(ES)

10. SPONSORING/MONITORING AGENCY REPORT NUMBER

National Aeronautics and Space Administration

Washington, DC 20546-0001

NASA TM-4504

11. SUPPLEMENTARY NOTES

Presented as SAE921997 at the Society of Automotive Engineers Aerotech '92, Anaheim, CA, Oct. 5-8, 1992.

12a. DISTRIBUTION/AVAILABILITY STATEMENT

12b. DISTRIBUTION CODE

Unclassified - Unlimited

Subject Category 06

13. ABSTRACT (Meximum 200 words)

Optical techniques for measuring airdata parameters have been demonstrated with promising results on highperformance fighter aircraft. These systems can measure the airspeed vector, and some are not as dependent on special in-flight calibration processes as current systems. Optical concepts for measuring freestream static temperature and density are feasible for in-flight applications. The best feature of these concepts is that the airdata measurements are obtained nonintrusively, and for the most part well into the freestream region of the flow field about the aircraft. Current requirements for measuring airdata at high angle of attack, and future need to measure the same information at hypersonic flight conditions place strains on existing techniques. Optical technology advances show outstanding potential for application in future programs and promise to make common use of optical concepts a reality. This paper summarizes results from several flight-test programs and identifies the technology advances required to make optical airdata techniques practical.

\section{SUBJECT TERMS}

Aerosols; Airspeed, Calibration static pressure; Doppler velocimetry; Static temperature

\begin{tabular}{l|l|l}
\hline 17. SECURITY CLASSIFICATION & 18. SECURITY CLASSIFICATION \\
OF REPORT & $\begin{array}{l}\text { 19. SECURITY CLASSIFICATION } \\
\text { OF PAGE } \\
\text { Unclassified }\end{array}$ & $\begin{array}{l}\text { UF ABSTAACT } \\
\text { Unclassified }\end{array}$
\end{tabular}

